\title{
CONCEPTUAL AND EXPERIMENTAL FEASIBILITY STUDY OF A SUPERCONDUCTIVE MICRO-UNDULATOR
}

\author{
T. Hezel, R. Rossmanith, B. Krevet, H. O. Moser \\ Forschungszentrum Karlsruhe, Projektgruppe Errichtung ANKA, \\ Postfach 3640, D-76021 Karlsruhe, Germany
}

\section{Abstract}

Generating synchrotron radiation from conventional undulators in the hard X-ray region requires high electron energies. In order to open this spectral region for sources with smaller electron energy, such as ANKA (2.5 GeV), the period length of the undulator has to be decreased. In this paper the concept and the first successful tests towards constructing a superconductive micro-undulator with a period length of $3.8 \mathrm{~mm}$ are described. The structures were built with a commercially available NbTi wire. It was possible to run about 1000 AmpËre through the undulator coil at $4 \mathrm{~K}$. A full prototype of a superconductive undulator is now under construction.

\section{INTRODUCTION}

This study was stimulated by various ideas on how to build a micro-undulator (an undulator with a period length significantly less than $1 \mathrm{~cm}$ ) $[1,2]$. Since a first design study of a superconductive micro-undulator in $1991[3,4]$, the interest in micro-undulators has grown very considerably $[5,6]$.

\subsection{The Principle}

Fig. 1 shows a schematic drawing of the design presented in this paper. The wire is wound in grooves around a cylinder. The direction of the current alternates along the electron trajectory.

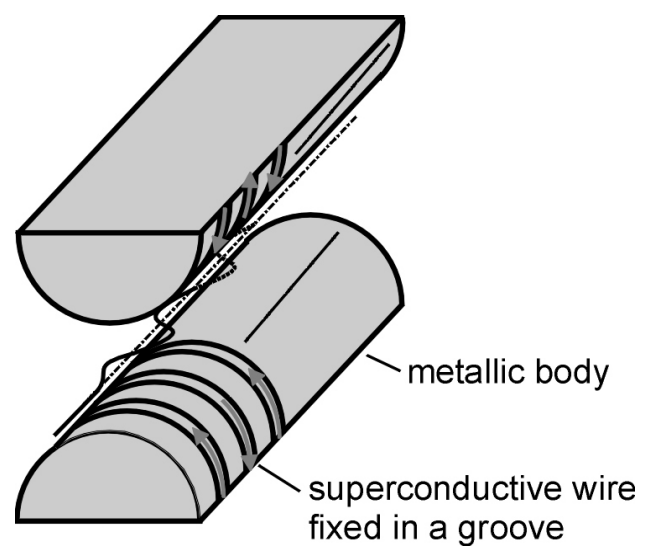

Fig. 1: Principle of the superconductive micro-undulator.

In this first prototype the metallic body of the undulator has a cylindrical form to save machining cost. In a later version the metallic body will have a flat profile similar to conventional undulators.
According to the law of Biot-Savart, an electrical current in a wire generates a circular magnetic field. The vertical field components add in the middle of the gap and result in a magnetic field alternating in the vertical direction along the beam axis.

\subsection{Emitted Spectrum}

Insertion devices can expand the spectral region of storage rings to higher energies. The photons emitted by an ANKA [7] bending magnet have a critical energy of about $6 \mathrm{keV}$. According to the standard formula for the fundamental wavelength $\lambda$ of an undulator (period length $\lambda_{\mathrm{u}}=3.8 \mathrm{~mm}$ )

$\lambda=\frac{\lambda_{u}}{2 \gamma^{2}}\left[1+\frac{K^{2}}{2}+\gamma^{2} \Theta_{0}^{2}\right] ; K \approx 0.934 \cdot B_{0}[T] \cdot \lambda_{u}[\mathrm{~cm}](1)$

$\lambda$ is $0.8 \AA(\approx 15 \mathrm{keV})$ at an energy of $2.5 \mathrm{GeV}$.

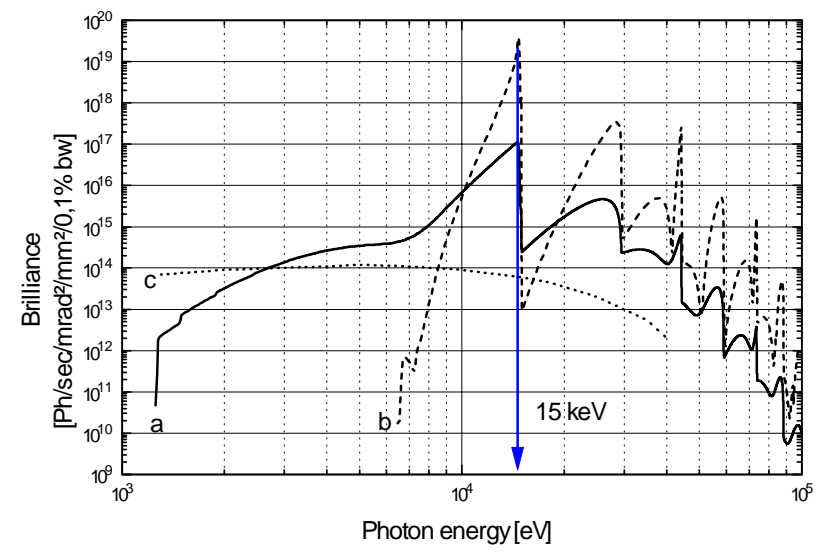

Fig. 2: Brilliance of a 100-period undulator: $\mathrm{I}=400 \mathrm{~mA}$, $\lambda_{\mathrm{u}}=3.8 \mathrm{~mm}, \beta_{\mathrm{x}}=1.5 \mathrm{~m}, \beta_{\mathrm{y}}=0.5 \mathrm{~m}, \mathrm{~B}_{0}=1 \mathrm{~T}$ and $\mathrm{E}=2.5 \mathrm{GeV}$ calculated with URGENT [8]. a) $\varepsilon=80 \mathrm{nmrad}$; b) $\varepsilon=5 \mathrm{nmrad}$; c) ANKA bending magnet at $\varepsilon=80 \mathrm{nmrad}$.

\section{CURRENT LIMITATION}

For the undulator prototype a commercially available NbTi superconductor with a cross-section of $1.25 \times 0.80$ $\mathrm{mm}^{2}$ (including insulation) has been chosen [9]. Since superconductors are usually used in a high magnetic field environment, the quench behaviour in the low field region (where the undulator operates) is not well documented. Therefore, the quench behaviour was measured as a function of an external field. 


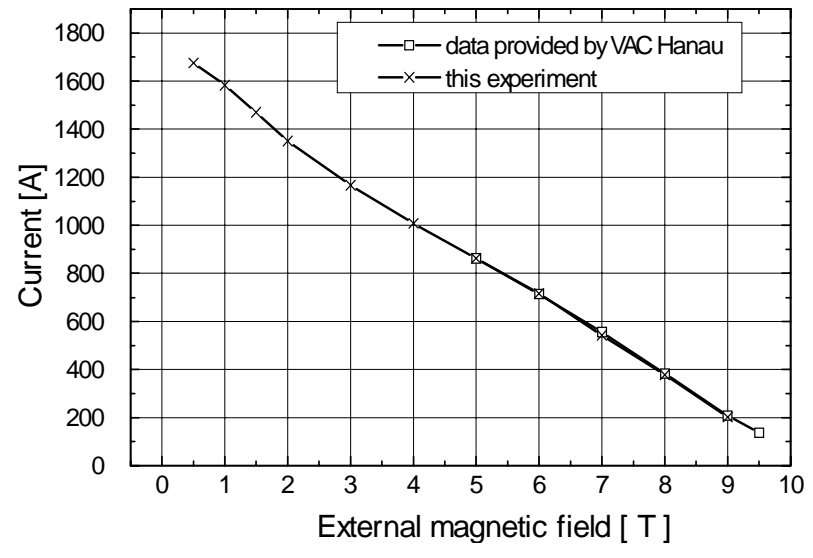

Fig. 3: Measurement of the quench current as a function of an external magnetic field.

\section{WIRE ARRANGEMENT}

The wire described in chapter 3 can be arranged in various ways (fig. 4). Each arrangement will result in a different maximum field in the gap, a different maximum field in the wire package (and therefore in a different current limit according to fig. 3) and a different undulator period.

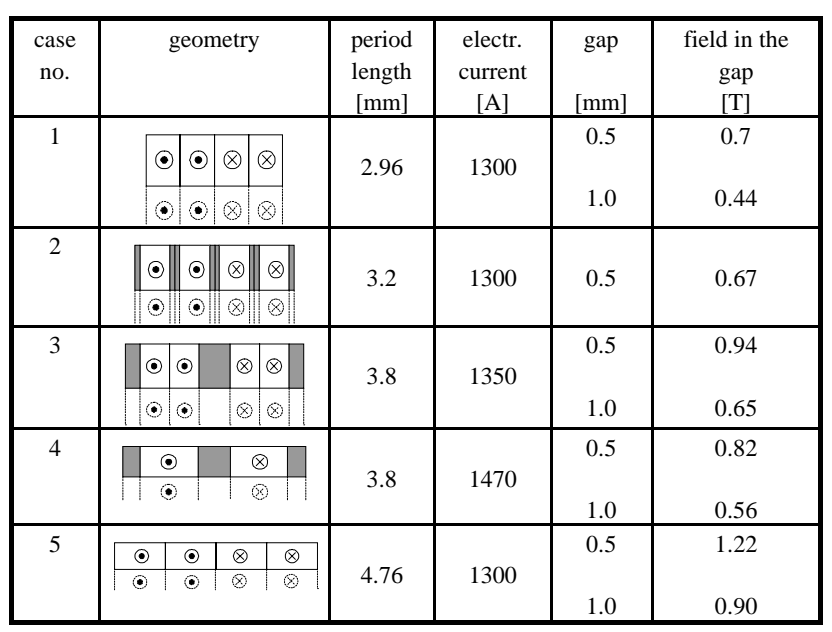

Fig. 4: Various possible wire arrangements in an undulator. The geometry is shown for one period only. The shaded areas represent insulation material. The first layer is fully drawn, the second partly, the third and fourth layers are omitted. The calculations were performed with MAFIA [10].

\section{QUENCH TEST FOR AN UNDULATOR WINDING}

In the first test the simple wire arrangement shown in fig. 5 was used.

This wire arrangement has the advantage that it is easier to coil, but the disadvantage that the achievable field strength in the gap is lower compared to all other wire arrangements shown in fig. 4.
The experiment proved that it was possible to run 1000 A through the undulator winding.

\begin{tabular}{|c|c|c|c|c|c|c|c|c|c|}
\hline 0 & Q & 0 & (Q) & 0 & Q & 0 & Q & 0 & Q \\
\hline 0 & (2) & 0 & (Q) & 0 & (2) & 0 & (2) & 0 & (2) \\
\hline 0 & $\otimes$ & 0 & (2) & 0 & (Q) & 0 & (2) & 0 & (2) \\
\hline 0 & (2) & 0 & (2) & 0 & 8 & 0 & $\otimes$ & 0 & $\otimes$ \\
\hline
\end{tabular}

Fig. 5: Wire arrangement used for the quench test of the undulator winding. The measured quench current was 1000 A.

\section{UNDULATOR PROTOTYPE WITH IRON}

After this first test a 100-period undulator with a period length of $3.8 \mathrm{~mm}$ was built by using the winding configuration no. 4 from fig. 4 . In order to increase the field strength in the gap, iron was used. The undulator body consists of six different parts: a copper core, an iron and four aluminium half-cylinders (figs. 6 and 7).

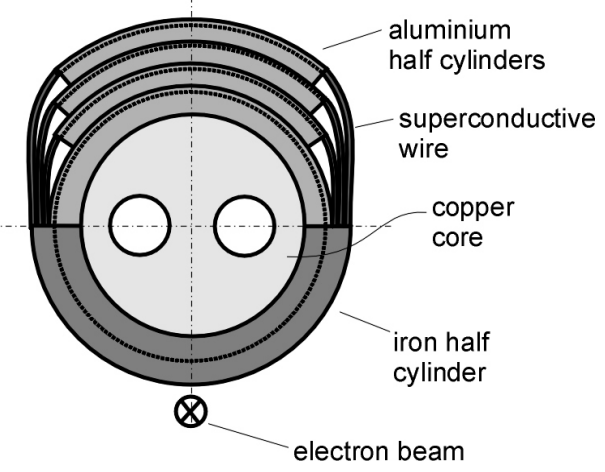

Fig. 6: Cross-section of the assembled undulator. A copper core cooled by liquid helium is located in the center. The iron half-cylinder is placed next to the electron beam.

The copper core contains two tubes through which the liquid helium flows. The iron half-cylinder has straight grooves perpendicular to the electron beam, whilst the aluminium parts have helical grooves. The grooves keep the superconductive wire fixed.

The maximum field strength in the $1 \mathrm{~mm}$ gap is $1 \mathrm{~T}$. Calculations performed with MAFIA [10] have shown that the peak field close to the wires is about three times higher than the maximum field in the center of the gap (fig. 8).

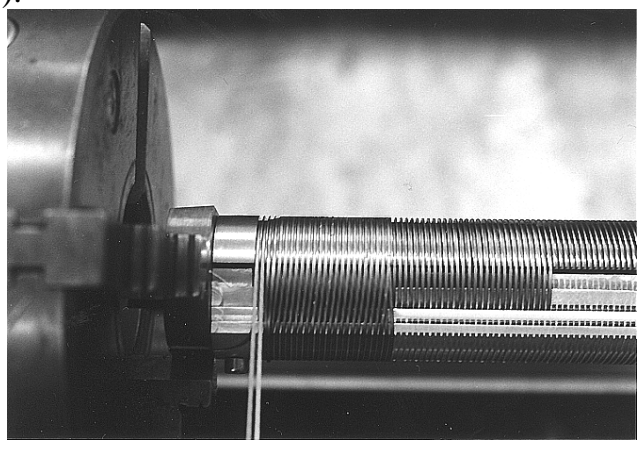

Fig. 7: Photograph of the undulator prototype during coiling. 


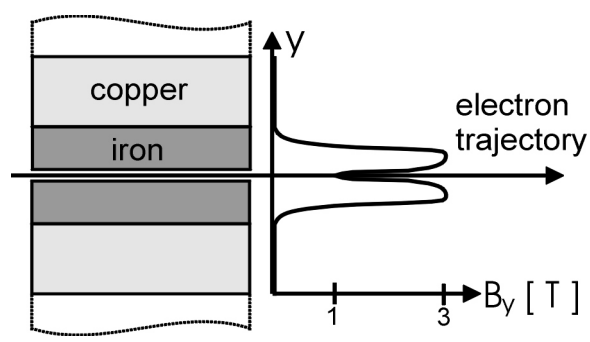

Fig. 8: Vertical cut through the undulator and corresponding vertical magnetic field calculated with MAFIA.

\section{THE CRYOSTAT}

Fig. 9 shows the cryostat of the superconductive undulator. The cryostat is presently under construction.

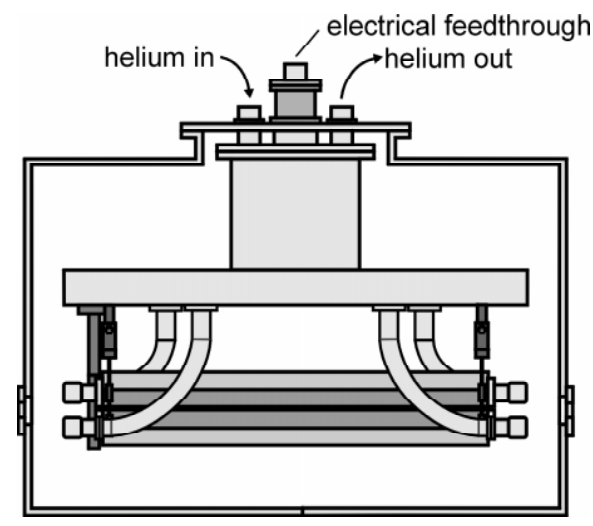

Fig. 9: Sideview of the cryostat (under construction).

The undulator is housed in a vacuum tank. The container for the helium (shown in grey) is in the upper part of the tank. From this container the helium flows via flexible tubes into the body of the undulator. A current in excess of $1000 \mathrm{~A}$, which is needed to operate the undulator, is transported through a large number of copper wires located in the He-tank. This arrangement reduces the heat transport from outside and, in addition, reduces the electrical resistance of the copper wires. At their cold end, the copper wires are soldered to two hollow, heliumfilled copper cylinders. The ends of the cylinders are positioned in close proximity to the undulator.

Also, in order to reduce the heat transport, the undulator is mechanically fixed to the helium tank. The undulator gap can be varied by several millimeters.
Thin metal sheets fixed to the helium container (not shown in fig. 9) protect the undulator from the heat radiated from the walls of the vacuum tank.

If an arrangement is envisaged in which the undulator and the accelerator vacuum system are separate, a thin metal foil $(<50 \mu \mathrm{m})$ can be inserted between the two systems. Since the pressure difference between the two vacuum systems is small, the mechanical force acting on this foil is almost negligible.

\section{SUMMARY}

It was experimentally shown that an undulator with a period length of $3.8 \mathrm{~mm}$ built with superconductive wires can produce a maximum field of $1 \mathrm{~T}$. At the moment a 100-period prototype undulator is under construction which is soon to be tested. The undulator is housed in a vacuum tank which can be either part of the accelerator vacuum system or, if required, the tank and the accelerator vacuum system can be separated by a thin metal foil.

\section{REFERENCES}

[1] V. L. Granatstein et al., Small-period electromagnet wigglers for free-electron lasers, Appl. Phys. Lett. 47 (6), Sept. 1985

[2] R. Tatchyn et al., Attainment of Submillimeter Periods and a 0.3T Peak Field in a Novel Micropole Undulator Device, Appl. Phys. Lett. 50(7), pp. 377-379, 1987

[3] H. Holzapfel, Diploma thesis, Entwurf eines supraleitenden Mikroundulators zur Erzeugung harter Synchrotronstrahlung, Universit\%ot Karlsruhe, 1991

[4] H. O. Moser, B. Krevet, H. Holzapfel, Mikroundulator, Patentschrift DE 4101094 C1, Kernforschungszentrum Karlsruhe, 1991

[5] P. M. Stefan, L. Solomon, S. Krinsky, G. Rabowski, NSLS Prototype Small-Gap Undulator (PSGU), Proc. IEEE Part. Accel. Conf., San Francisco, CA, 1991, p. 1096

[6] $10^{\text {th }}$ ICFA Beam Dynamics Panel, Workshop, General presentation of ESRF Insertion Devices, p. WG7-1, 1996, ESRF

[7] D. Einfeld et al., ANKA Status, these proceedings

[8] URGENT, R. P. Walker, B. Diviacco, Proc. $4^{\text {th }}$ Int. Conf. Synchrotron Radiation Instrumentation, Chester, July 1991

[9] VAC Hanau, Germany, private communication

[10] MAFIA, CST Gesellschaft $f_{s} r$ Simulationstechnik mbH, Darmstadt, Germany 